\title{
Transvenous lead removal with a fragment of a papillary muscle - a silent complication
}

\author{
Monika Gawalko, ${ }^{1, C-D}$, Agnieszka Kołodzińska1,D-F, Marcin Grabowski²,A-F, Andrzej Kutarski2,E-F, Grzegorz Opolski,F \\ A - Research concept and design, B - Collection and/or assembly of data, C - Data analysis and interpretation, \\ D - Writing the article, E - Critical revision of the article, F - Final approval of article
}

1 Medical University of Warsaw

2 Department of Cardiology, Medical University of Lublin

3 1st Department of Cardiology, Medical University of Warsaw

Address for correspondence:

Monika Gawalko, Medical University of Warsaw

email: mongawalko@gmail.com

Agnieszka Kołodzińska, Medical University of Warsaw

email: aa.kolodzinska@wp.pl

Marcin Grabowski, 1st Department of Cardiology, Medical University of Warsaw

email: marcin.grabowski@wum.edu.pl

Andrzej Kutarski, Department of Cardiology, Medical University of Lublin

email: a_kutarski@yahoo.com

Grzegorz Opolski, 1st Department of Cardiology, Medical University of Warsaw

email: cardiology@wum.edu.pl

Received: 15.12 .2016

Revised: 29.12.2016

Accepted: 29.12.2016

Key words:

pacemaker, transvenous lead extraction, complications of lead extraction

\section{Introduction}

Tricuspid valve (TV) insufficiency is one of the more important complications in patients with cardiac implantable electronic devices due to the endocardial lead ${ }^{[1]}$. The frequency of this complication is growing with the increasing number of implanted and removed leads crossing the TV ${ }^{[2]}$ and with

\section{Case Report}

76-year-old male patient with ischaemic heart disease, heart failure (NYHA II), chronic kidneys disease, diabetes mellitus type 2 and long history of pacemaker implantation was referred to the Clinic of Cardiac Surgery for pacemaker extraction. He had received his first single-chamber pacemaker implanted in his left infraclavicular area at age 66 owing to bradyarrythmia, developed during the course of permanent atrial fibrillation associated with Morgagni-Adams-Stokes syndrome. Within two years, the generator pocket was infected as a consequence of recurrent furunculus, pacemaker was removed leaving leads that deeply grew into the heart tissue. New device was placed in the right side of chest, but subsequent infection (Figure 1.) required extraction once again with the re-implantation of the device on the left side. trauma upon removal of the old lead that increasingly grows into the heart tissue. However, in some cases, even serious heart damage, tricuspid regurgitation and other symptoms are not observed ${ }^{[3]}$.

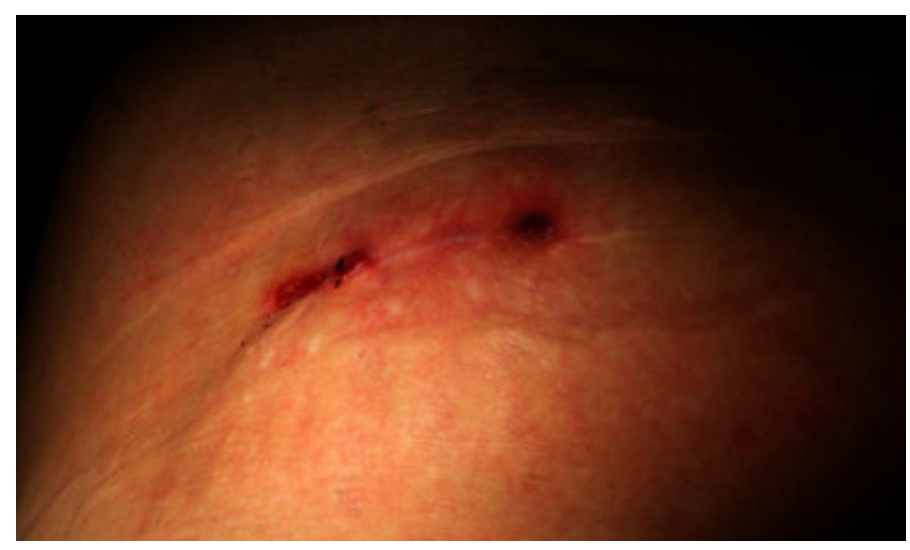

Figure 1 Dehiscence of infected skin with exposure of generator pocket. 
In the process of three hour operation all retained leads were removed (Figure 5.). Although, their extraction resulted in the

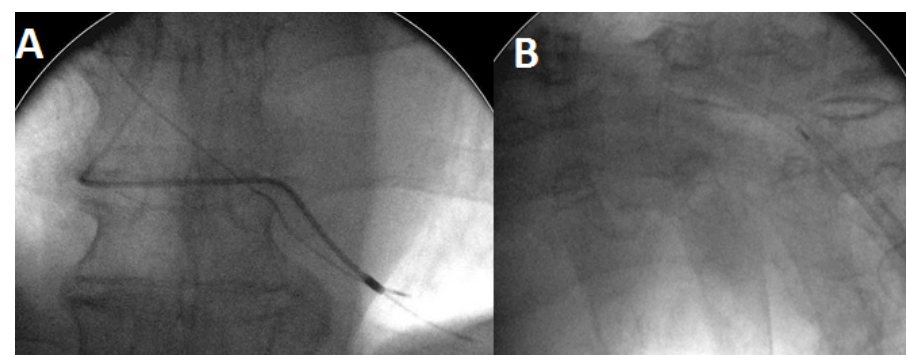

Figure 5 Anterior fluoroscopic images taken: $(A)$ before and $(B)$ after complete pacemaker lead andold electrode removal; $(A)$ the tip of the electrode in the right ventricle

asymptomatic removal of a $3 \mathrm{~cm}$-fragment of a papillary muscle attached to the oldest lead (Figure 2. Figure 3), the operation

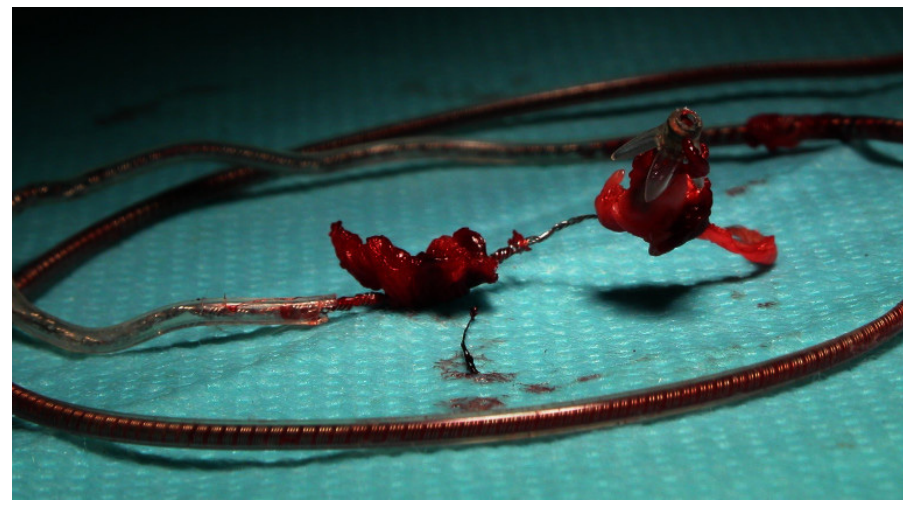

Figure 2 Removed lead with fragment of a papillary muscle $(1,5 \times 2 \mathrm{~cm})$.

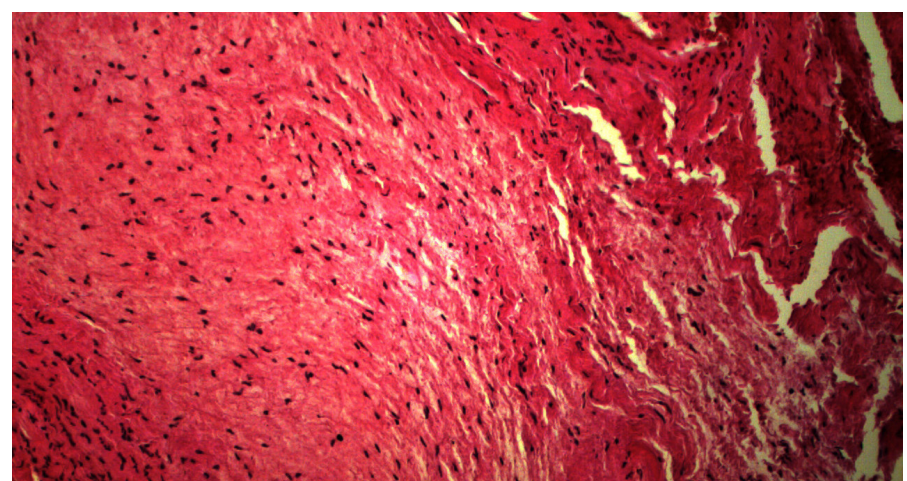

Figure 3 Histopathological findings. Amplification 20x. Section of a fibrous sheath covering the leadtip adjacent to a papillary muscle. Domination of connective tissue capsule. Cardiomyocyteshypertrophy, fibrosis, hemorrhages, without evidence of active inflammation.

was completed without additional complications. After one week observation patient was discharged with new implanted pacing system on the left side. More than six months later, during a control medical appointment, transthoracic echocardiography (TTE) was made and raveled slight damage to the wall of the right ventricle (Figure 4.).That damage was healing properly for the next half a year without any symptoms of right heart failure or other complications.

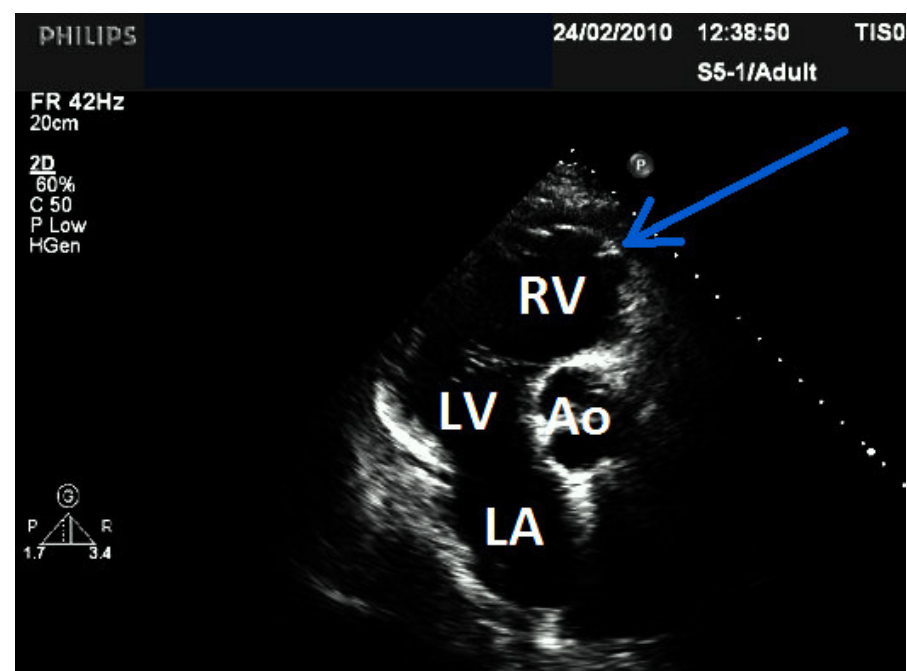

Figure 4 Transthoracic echocardiographic, parasternal long axis view used to visualize damage to thewall of the right ventricle (blue arrow) after transvenous lead extraction. $\mathrm{LV}$, left ventricle; LA, left atrium; RV, right ventricle, Ao, aorta

\section{Conclusions}

Lead extraction is a complex surgical procedure with some unavoidable risks, but it is not a rule that each time the lead is separated from scar tissue there is a high chance of tearing the surrounding blood vessel or perforating the heart, which can result in tamponade or tricuspid valve insufficiency. Some mechanical TLE complications may turn out fortunately to be asymptomatic, but one should always be aware of them.

\section{References}

1. Polewczyk A, Kutarski A, Tomaszewski A, Brzozowski W, Czajkowski M et all. Lead dependent tricuspid dysfunction: Analysis of the mechanism and management in patients referred for transvenous lead extraction. Cardiology journal. 2013;20(4):402-10

2. Al-Mohaissen MA, Chan KL. Prevalence and mechanism of tricuspid regurgitation following implantation of endocardial leads for pacemaker or cardioverter-defibrillator. J Am Soc Echocardiogr, 2012ł 25: 245-252.

3. Kucukarslan N, Kirilmaz A, Ulusoy E et al. Tricuspid insufficiency does not increase early after permanent implantation of pacemaker leads. J Card Surg, 2006; 21: 391-394. 